\title{
Herpes Simplex (Hsv-1, 2) Seropositivity: A Study Carried Out Among Diabetic and Non-Diabetic Patients in A Community In Southwest Nigeria
}

\author{
A. J. $\mathrm{OKE}^{1}$, A. A. $\mathrm{OKE}^{2}$ \\ I(Faculty of Basic Clinical Sciences, Bowen University Teaching Hospital, Ogbomoso, Nigeria) \\ ${ }_{2}^{2}$ (Department of Biological Sciences, College of Natural Science, Redeemer's University, Mowe. Nigeria).
}

\begin{abstract}
Herpes simplex virus infections have been previously reported in diabetic patients. This study therefore investigated the prevalence of Herpes simplex virus $(H S V-1,2)$ in patients attending a diabetic clinic of a medical centre in a community in southwest Nigeria. Three hundred and twenty (320) patients aged between 35 - 50 years were screened for fasting blood sugar (FBS); urine sugar (US), urine ketone (UK) and antibodies to HSV-1, 2. Two hundred and seventy (270) (84.4\%) of the patients had hyperglycaemia as well as glucosuria, with FBS ranging between 125 and $560 \mathrm{mg} / \mathrm{dl}$, while the remaining 50 (15.6\%) had normoglycaemia, with FBS ranging between 55 and $90 \mathrm{mg} / \mathrm{dl}$. None of the normoglycaemic group was $\mathrm{HSV}-1$, 2 seropositive. Among the 270 hyperglycaemic group, 55 (20.4\%) had ketonuria and all (100\%) were HSV-1, 2 seropositive. 215 (79.6\%) of hyperglycaemic group had no ketonuria, and none of them was HSV-1, 2 seropositive. Results of this study showed a high prevalence of hyperglycaemia in the community. Seropositivity to HSV-1, 2 is significant in ketonuria hyperglycaemic patients. This can form a basis for investigating the role of $H S V-1,2$ in uncontrolled diabetes since ketonuria is associated with uncontrolled diabetes.
\end{abstract}

Keywords: Fasting blood sugar, HSV-1, 2 Seropositivity, Ketonuria, Urine sugar

\section{Introduction}

Diabetes is a group of metabolic diseases characterized by hyperglycemia resulting from defects in insulin secretion, insulin action or both. The chronic hyperglycaemia of diabetes is associated with long-term damage, dysfunction and failure of different organs, especially the eyes, kidneys, nerves, heart and blood.

Several pathogenic processes are involved in the development of diabetes. These range from autoimmune destruction of the $\beta$-cells of the pancreas with consequent insulin deficiency to abnormalities that result in resistance to insulin action. The basis of the abnormalities in carbohydrate, fat, and protein metabolism in diabetes is deficient action of insulin on target tissues. Deficient insulin action results from inadequate insulin secretion and/or diminished issue responses to insulin at one or more points in the complex pathways of hormone action. Impairment of insulin secretion and defects in insulin action frequently coexist in the same patient.

Symptoms of marked hyperglycaemia include polyuria, polydipsia, weight loss, and blurred vision. Acute, life-threatening consequences of uncontrolled diabetes are hyperglycaemia with ketoacidosis or the nonketonic hyperosmolar syndrome.

The vast majority of cases of diabetes fall into two broad etiopathogenic categories: Type 1 diabetesthe cause of which is an absolute deficiency of insulin secretion and Type 2 diabetes which is more prevalent is caused by a combination of resistance to insulin action and an inadequate compensatory insulin secretion response. In this category, a degree of hyperglycaemia sufficient to cause pathologic and functional changes in various target tissue, but without clinical symptoms, may be present for a long period of time before diabetes is detected [1,2]. Several millions of people have diabetes globally including Africa [3-5].

There have been reports of Herpes virus infections in diabetic patients [6-9]. HSV-1 has been recognized as a potential pathogen of cardiovascular diseases. The presence of antibody to HSV -1 is reported to be associated with an increase in the risk of incidence myocardial infarction and coronary heart death. Type 2 diabetes is a major risk infection for cardiovascular morbidity and mortality [6].

To improve the understanding of the relationship between HSV-1, 2 and diabetes, this study investigated the prevalence of HSV-1,2 in diabetic and non-diabetic patients in a community in southwest Nigeria. 


\subsection{Materials}

\section{Materials And Methods}

HSV-1, 2 IgG EIA diagnostic kit (Clinotech diagnostic \& Pharm. Inc., Canada, expiry 12/2014);

Combi Uriscreen (Axiom Medical Ltd. UK, expiry; 6/2014);

Glucose kit (Randox Lab Ltd, Antrim, UK);

Stat Fax ELISA reader 2004 (Awareness Tech Inc., USA);

Spectrophotometer SP830+ (Metertech, Taiwan).

\subsection{Methods}

This study was carried out at a diabetes clinic in Ogbomoso, a cosmopolitan town in the Southwestern part (Oyo State) of Nigeria. Formal consent was obtained from the Medical Director of the centre. A total of three hundred and twenty (320) volunteered persons were involved in the study and informed consents were obtained from them. The subjects, males and females, were between the ages of 35 and 50 years. No pregnant woman was involved.

In each case Fasting blood was collected in fluoride tubes, and in plain serum tubes. Urine sample was also collected from each person. Serum was kept frozen until analysis.

Plasma FBS were determined using Glucose oxidase method as described by Barham and Trinder ${ }^{10}$ (Glucose Kit, Randox Lab Ltd, UK). Absorbance was read using spectrophotometer SP 830+. Qualitative urine sugar and ketone were done using COmbi uriscreen reagent strips (Axiom Medical Ltd, UK). Sensitivity of strip is as follows:

Glucose: $12.6 \mathrm{mg} / \mathrm{dl}$; ketone $1.0 \mathrm{mg} / \mathrm{dl}$. Each batch of reagent was controlled with known negative and positive sugar and ketone specimens. The presence or absence of antibodies to HSV-1, 2 were determined in the serum using IgG EIA Kit, according to the manufacturer's instructions with appropriate controls (HSV-1, 2 EIA Kit, Clinotech diagnostic and Pharmaceutical Inc., Canada).

The results were read by ELISA Microwell reader compared with calibrator and controls ${ }^{11-14}$. IgG seropositivity to HSV-1, 2 indicated prior infection of HSV-1, 2.

\section{Results}

In this study, 270 (84.4\%) of the 320 patients studied had hyperglycaemic with FBS ranging from 125 to $560 \mathrm{mg} / \mathrm{dl}$, while $50(15.6 \%$ ) had normoglycaemic with FBS ranging from $55-90 \mathrm{mg} / \mathrm{dl}$ (Table 1). Among the 270 patients with hyperglycemia, $55(20.4 \%)$ had ketonuria, and all of them (100\%) were seropositive for HSV-1, 2. The remaining 215 (79.6\%) patients had no ketonuria, and none of them was seropositive for HSV1, 2. None of the 50 normoglycaemic patients was seropositive for HSV-1, 2 (Table 2). Few numbers of patients were seropositive in the FBS 125 - $399 \mathrm{mg} / \mathrm{dl}$ range compared with the number recorded in the much higher FBS values, the highest number of patients being recorded in the $500-560 \mathrm{mg} / \mathrm{dl}$ range (Table 3 ). The T-test value obtained was $\mathrm{p}=0.000$ at a significance level of $\mathrm{p}<0.05$.

In this study, the presence of HSV-1, 2 antibodies was associated with hyperglycaemic ketonuria, and there was a high prevalence of hyperglycaemia among the patients studied. Urine sugars were qualitatively positive for all the 270 hyperglycaemic patients.

Table 1: Showing prevalence of hyperglycaemic among patients $(n=320)$

\begin{tabular}{|c|c|c|c|c|}
\hline Type & $\mathbf{n}$ & $\begin{array}{c}\text { FBS (mg/dl) } \\
\text { Minimum }\end{array}$ & $\begin{array}{c}\text { FBS (mg/dl) } \\
\text { Maximum }\end{array}$ & FBS Mean \\
\hline Hyperglycaemia & 270 & 125 & 560 & 274.27 \\
Normoglycaemia & 50 & 55 & 90 & 64.40 \\
\hline
\end{tabular}

Table 2: Showing Seropositivity of HSV-1, 2 in diabetic and non-diabetic patients $(\mathrm{n}=320)$

\begin{tabular}{|l|c|c|}
\hline \multicolumn{1}{|c|}{ Type } & No. of Patients & HSV-1, 2 Seropositivity \\
\hline Normoglycaemia & 50 & $0(0 \%)$ \\
\hline Hyperglycaemia non-ketonuria & 215 & $0(0 \%)$ \\
\hline Hyperglycaemia ketonuria & 55 & $55(100 \%)$ \\
\hline
\end{tabular}

Table 3: Showing distribution of FBS among patients $(n=55)$ seropositive HSV-1, 2

\begin{tabular}{|c|c|}
\hline FBS range (mg/d) & No of Patients \\
\hline $125-299$ & 5 \\
\hline $300-399$ & 5 \\
\hline $400-499$ & 20 \\
\hline $500-599$ & 25 \\
\hline
\end{tabular}




\section{Discussion}

A high incidence (84.4\%) of hyperglycaemic was recorded in this study, which is an indication of a high rate of diabetes in this community (Table 1 ). The T-test value obtained was $p=0.000$ at a significance level of $\mathrm{p}<0.05$. This supports the prevalence of diabetes worldwide reported by other workers. Chijioke et al [15] and Ebenezer et al [16] reported a high prevalence of diabetes in their works in cosmopolitan cities of Ilorin in southwest and Port Harcourt in South-South Nigeria respectively. Serah et al [4] reported that a total number of people with diabetes worldwide is projected to rise from 171 million in the year 2000 to 366 million in 2030 . Similarly, Hilary et al [5] reported that the number of adults with diabetes in the world will rise from 135 million in 1995 to 300 million in the year 2025, and that the major part of this numerical increase will occur in developing countries.

In our study, the 50 normoglycaemic patients were seronegative to HSV $-1,2$, similarly the 215 nonketonuria hyperglycemic patients were seronegative to HSV-1, 2. Whereas all the 55 (100\%) ketonuria hyperglycaemic were seropositive to HSV $-1,2$ (Table 2). A significant association of HSV-1, 2 seropositivity with ketonuria hyperglycaemia was found in this study. This agrees with the reports of other workers: Eugene et al [3] reported an association of herpes virus with DM-2 in patients of Sub-Saharan African origin where they recorded $87.7 \%$ seropositivity to HHV-8 in ketosis-prone DM-2. Yuhua et al [6] also reported an association of herpes simplex with diabetes.. There is therefore a relationship of herpes simplex with diabetes, althonugh HSV infections are seen in non-diabetic conditions, such as keratitis and sexually transmitted diseases [17].

\section{Conclusion}

In this study, we recorded few numbers of patients that were seropositive in the FBS $125-399 \mathrm{mg} / \mathrm{dl}$ range compared with the number recorded in the much higher FBS $500-560 \mathrm{mg} / \mathrm{dl}$ range (Table 3). There is need to investigate the role of herpes virus in diabetes further.

Further study is necessary to establish relationship of HSV-1, 2 with different FBS levels of hyperglycaemia. Although, American Diabetes Association ${ }^{1}$ reported that consequences of uncontrolled diabetes include hyperglycaemia with ketoacidosis.

\section{Acknowledgements}

We acknowledge Mr. J. A. Adegboye of Bowen University Teaching Hospital for his technical assistance on EIA assay; Dr. E. A. Amao for granting us consent for this study in his hospital and for his assistance in the procurement of HSV diagnostic kit.

\section{References}

[1] American Diabetic Association. Diagnosis and Classification of diabetes mellitus. Diabetes Care 34, $2011,562-564$.

[2] K.G. Alberti and P.Z. Zimmet. Definition, diagnosis and classification of Diabetes mellitus and its complications. Diabetic medicine, 15(7), 1998, $539-553$.

[3] E. Sobngwi, S.P. Choukem, F. Agbalika, B. Blondeau, L.S. Lebbe, D. Thiam, P.Cattan, J. Larghero, F. Foufelle, P. Ferre, P. Vexiau, F. Calvo and J.F. Gautier. Ketosis-prone type 2 Diabetes mellitus and human herpes virus infection in sub-saharan Africans. JAMA, 299(23), 2008, 2770 - 2776

[4] W. Sarah, R. Gojka, G. Anders, S. Richard and K. Hilary. Global Prevalence of Diabetes: Estimates for the year 2000 and projections for 2030, Diabetes Care, 27(5), 2004, 1047 - 1053.

[5] K. Hilary, R.E. Aubert and W.H. Herman. Global Burden of Diabetes, 1995 - 2025: Prevalence, Numerical Estimation and Projections. Diabetes Care 21(9), 1998, $1414-1431$

[6] S. Yuhua, W. Yongjian, P. Weidong and Y. Yuejin. An association of herpes simplex virus Type 1 infection with type 2 diabetes. Diabetes Care, 28(2), 2005, 435 - 436.

[7] A. DeOcampo and B. Bradford. Genital herpes and Diabetic ketoacidosis: A patient report. Clinical Paediatrics (Phila) 38(11), $1999,661-663$.

[8] S. Tesfaye, D.R. Cullen, R.M. Wilson and P.D. Woolley. Diabetic ketoacidosis precipitated by Genital herpes infection. Diabetes Research and Clinical Practice, 13(1-2), 1991, 83 - 84.

[9] H.S. Jun and J.M Yoon. A new look of viruses in Type 1 diabetes. Diabetes/Metabolism. Research and reviews, $19(1), 2003,8-31$.

[10] D. Barham and P. Trinder. An improved color reagent for determination of blood glucose by the oxidase system. Analyst 97(151), $1972,142-145$

[11] R.M. Coleman, L. Pereira, P.D. Baily, D. Dandero D, C.Wickliffe and A.J.Nahmias. Determination of herpes simplex virus typespecific antibodies by Enzyme-Linked Immunosorbent Assay (ELISA). Journal of Clinical. Microbiology, $18(2), 1983,287$.

[12] B.F. Vestergaad, P.C. Grauballe and H. Spanggard. Titration of herpes simplex virus antibodies in human sera by the EnzymeLinked Immunosorbent Assay (ELISA). Acta Pathol Microbiol Scand B. . 85B(6), 1977, 446 - 448.

[13] A.J. Nahmias, J. Dannenbarger, C.Wickliffe and M, Muther. Clinical aspect of infection with herpes simplex viruses 1 and 2 in the human herpes virus (Feds, NY: Elsevier, 1981, pp $3-9$.

[14] R. Ashley-Morrow, J. Nollkamper, N.J. Robinson, N. Bishop and J. Smith. Performance of Focus ELISA tests for herpes simplex virus type 1 and 2 antibodies among women in ten diverse geographical locations. Clinical Microbiology and Infection. 10(6), 2004, $530-536$.

[15] A. Chijioke, A.N. Adamu and A.M. Makusidi. Mortality pattern among Type 2 Diabetes patients in Ilorin, Nigeria. JEMDSA 15, 2010,2 .

[16] E.A. Nyenwe, O.J. Odia, A.E. Ihekwaba, A. Ojule and S. Babatunde. Type 2 Diabetes in adult Nigerians: A study of its prevalence and risk factors in Port Harcourt, Nigeria. Diabetes Research and Clinical Practice, 62(3), 2003, 177 - 185.

[17] B.A. Forbes, F.S. Daniel and S.W. Alice, Diagnostic microbiology 10th ed, (Mosby, N.Y., 1998, pp 341, 368). 